\title{
Comparative Study of Knowledge Acquisition, Satisfaction, Self-confidence and Perceived Support in Nursing Students Experiencing Simulation Versus Clinical Placement in Perinatal Care
}

Catherine Pépin

catherine.pepin.4@umontreal.ca

Marilyn Aita

Université de Montréal, marilyn.aita@umontreal.ca

Andréane Lavallée

andreane.lavallee@umontreal.ca

Johanne Goudreau

University of Montreal, johanne.goudreau@umontreal.ca

Follow this and additional works at: https://qane-afi.casn.ca/journal

Part of the Education Commons, and the Nursing Commons

\section{Recommended Citation}

Pépin, Catherine; Aita, Marilyn; Lavallée, Andréane; and Goudreau, Johanne (2022) "Comparative Study of Knowledge Acquisition, Satisfaction, Self-confidence and Perceived Support in Nursing Students Experiencing Simulation Versus Clinical Placement in Perinatal Care," Quality Advancement in Nursing Education - Avancées en formation infirmière: Vol. 8: Iss. 1, Article 3.

DOI: https://doi.org/10.17483/2368-6669.1295

This Article is brought to you for free and open access by Quality Advancement in Nursing Education - Avancées en formation infirmière. It has been accepted for inclusion in Quality Advancement in Nursing Education - Avancées en formation infirmière by an authorized editor of Quality Advancement in Nursing Education - Avancées en formation infirmière. 


\section{Comparative Study of Knowledge Acquisition, Satisfaction, Self-confidence and Perceived Support in Nursing Students Experiencing Simulation Versus Clinical Placement in Perinatal Care}

\section{Cover Page Footnote}

We wish to thank Ivan Simoneau at the Cégep de Sherbrooke for the time he spent discussing the data collection tools and for sharing the validated French version of the Simulation Design Scale, the Educational Practices in Simulation Scale, the Student Satisfaction with Learning Scale, and the SelfConfidence in Learning Using Simulation Scale from the National League for Nursing. We also thank all the Faculté des sciences infirmières students at the Université de Montréal who agreed to participate in the study. Nous tenons à remercier Ivan Simoneau du Cégep de Sherbrooke pour le temps qu'il a passé à discuter des outils de collecte de données et à partager la version française validée de l'Évaluation conceptuelle de la simulation clinique, de l'évaluation des pratiques pédagogiques en simulation (Educational Practices in Simulation Scale), de l'Échelle de satisfaction des étudiantes à l'égard de leurs apprentissages, et de l'Échelle de confiance des étudiantes à l'égard de leurs apprentissages de la National League for Nursing. Nous remercions également toutes les étudiantes de la Faculté des sciences infirmières de l'Université de Montréal qui ont accepté de participer à l'étude. 


\section{Introduction and Context}

The high-quality clinical educating environments are essential for nursing students (Hartigan-Rogers et al., 2007; Horstmanshof \& Moore, 2016). These clinical environments, commonly called clinical placements, aim to improve students' competencies specific to the learning unit. The heterogeneity of the type and settings of clinical placements (Canadian Association of Schools of Nursing [CASN], 2015; Smith et al., 2013), in addition to the difficulty of guaranteeing clinical placements (Howard et al., 2011; Smith et al., 2010), is perhaps preventing the optimal development of student competencies. Furthermore, with the constant increase in student enrollment in nursing programs across Canada (CASN, 2016), clinical placements are sometimes unable to accommodate as many students as need placement (Smith et al., 2010). To deal with this challenge of clinical placements, there is an increased use of clinical simulation to educate nursing students for the clinical practice setting (CASN, 2015; Howard et al., 2011). During clinical simulations, students should be exposed to rich, curriculum-based clinical situations related to their course requirements (Cant \& Cooper, 2010). On one hand, clinical placements allow students to experience authentic learning situations while also getting a feel for their future working environment. On the other hand, simulations offer authentic clinical situations in environments that are safe and designed to fit the specific requirements of the learning unit (Cant \& Cooper, 2010; Hanshaw \& Dickerson, 2020; Jeffries, 2012). Although both methods foster the development of students' competencies, the above-mentioned constraints persist as an obstacle to the goal of offering the best conditions for the learning purposes.

\section{Background}

Clinical nursing simulations have been contrasted with clinical placements in previous reviews and studies. According to a systematic review of the literature, substituting a part of clinical placement by simulation did not appear to have a significant impact on knowledge acquisition, self-confidence, critical thinking, or clinical competencies of nursing students (Larue et al., 2015). However, conclusions of the review supported that exposing students to both modalities would reinforce their learning experience (Larue et al., 2015). A national study conducted in the United States indicated that substituting $25 \%$ or $50 \%$ of clinical placements with high-fidelity simulation did not modify students' educational outcomes in clinical competency and readiness for practice; the results of the program were similar to those of students receiving traditional education (Hayden et al., 2014). Another systematic review concluded that students' learning and outcomes are similar when a portion of clinical placement is replaced by simulation (Bogossian et al., 2019), yet the number of hours of simulation versus clinical placement for optimal knowledge and competencies acquisition by students remains undetermined. Similarly, and more specifically in perinatal care, no significant difference was observed for student knowledge and competencies when $25 \%$ of the clinical placement was replaced by high-fidelity simulation (Raman et al., 2019). However, to date, no studies across North America have compared the complete substitution of clinical placement by high-fidelity clinical simulation among nursing students in a perinatal care course. More research is warranted to explore the impact of having only clinical simulation in a perinatal course on students' learning and to provide guidance to ensure optimal acquisition of competencies.

The theoretical framework of the NLN-JSF clinical simulation (Jeffries, 2005, 2012) has been designed to guide the evaluation of nursing research on simulation, including components related to the teacher, the student, and the design characteristics (Young \& Shellenbarger, 2012), and it suggests outcomes associated with the clinical simulation experience: learning (knowledge 
acquisition), skill performance, learner satisfaction, critical thinking, and self-confidence. Inspired by this framework and to ensure comparisons with previous studies, we conducted a comparative study with the following aims: (a) to compare knowledge acquisition, satisfaction, and selfconfidence in a group of undergraduate nursing students who experienced two days of clinical simulations (SIM group) and a group who took part in a 10-day clinical placement (CPG), in addition to comparing the support they received from a clinical simulation tutor (SIM group) or a preceptor (CPG), the facilitator component of the Jeffries model (Jeffries, 2005, 2012); and (b) to evaluate, only for the SIM group, the elements of the simulation design characteristics as suggested in the NLN-JSF conceptual model.

Accordingly, the research questions were as follows: (a) What are the differences in knowledge acquisition, learning satisfaction, self-confidence, and perceived support from the preceptor/tutor between the SIM group and the CPG? (b) How does the SIM group evaluate the elements of the simulation design as suggested in the NLN-JSF?

\section{Methods}

\section{Design}

This study used a comparative study design to compare the outcomes between the SIM group and the CPG. The ethics certificate was obtained from the university's ethics board, and informed consent was obtained from all participating nursing students. As the study was conducted in a French academic setting, students completed all questionnaires in French.

\section{Simulation}

The simulations were conducted over two full days. Students underwent a 30-minute reflexive preparation (a pre-brief preparation), a 45-minute simulation, a 60-minute debriefing, and finally a 15-minute discussion about evaluations. Two days of simulation, with the preparation preceding the activities before and after the clinical simulation, met the academic credit requirements of the perinatal course. The scenarios of the clinical simulations included evaluation of labour and fetal well-being, vaginal delivery, assessment of the mother and newborn, breastfeeding, and pre-discharge education. The nursing students had the opportunity to prepare in advance with their teammates as they had access to the patient's medical file before the first day of simulation.

\section{Clinical Placement}

The nursing students who did not participate in the simulations did the usual 10-day clinical placement in a perinatal setting needed for the credit requirements of the perinatal course. Their clinical placement could take place during the day, evening, or night in 8- or 12-hour shifts. A formative evaluation was conducted on the 4 th day of the clinical placement and a summative evaluation on the 10th day. The clinical settings included the delivery room, the postpartum unit, and the neonatal unit. Each student visited only one of these settings.

\section{Setting and Participants}

The study took place in a faculty of nursing in Canada. All students enrolled in the perinatal care course at the fall semester 2017 were eligible and were recruited using a convenience sampling method. Students were invited to choose between the 10-day clinical placement and the 2-day clinical simulation. The research project was introduced to the eligible students at the beginning of the perinatal care course by one of the research team members. Reminders were sent 
via the university web platform and before the final exam. A total of 25 students participated in the SIM group and 55 in the CPG.

\section{Data Collection}

The data were collected at the end of the perinatal care course. Self-reported questionnaires were used to collect demographic data, as well as student satisfaction and self-confidence regarding their learning, perceived support, and the simulation design characteristics. The CPG students completed four questionnaires (demographic data, satisfaction, self-confidence, and perceived support) while the SIM group students completed the same four questionnaires in addition to the questionnaire on simulation design characteristics. Because of the lack of a validated and reliable tool available in French, the students' critical thinking was not measured. In addition, the skills performance was not evaluated since clinical procedures were not significantly contributing to the students' learning in the perinatal care designed course. The questionnaires were completed at the university where the study took place. A member of the research team distributed the questionnaires for both the SIM group and the CPG. The questionnaires took approximately 30 minutes to complete. Students sealed their completed questionnaires in an envelope and gave them to the research team member.

\section{Measurement of Outcomes}

\section{Knowledge Acquisition}

Students' learning related to the target objectives of the perinatal course was measured using the standardized evaluation of the clinical skills in the clinical simulation or clinical placement, the nursing care plan, and the final exam. The final exam focused on the theoretical concepts seen during the course, which covered all students' learning. The students of both the SIM group and CPG received a letter grade, which was then converted to its numerical equivalent using the university's guideline for comparing groups.

\section{Satisfaction}

Student satisfaction was measured using a self-reported questionnaire, which is a French version (ESEA) of the original English version of the Student Satisfaction with Learning Scale (Jeffries \& Rizzolo, 2006). This scale measured the students' satisfaction with their learning during the clinical simulations. The method for the transcultural translation and validation in French of this questionnaire is reported elsewhere, and the French version respects the same metrological qualities as the English version (Simoneau et al., 2012). In our study, the items were adapted for the clinical placement students. The ESEA is a five-point Likert-type scale, consisting of five items, for a total possible score of 25 points. A higher score indicates that the students are more satisfied with their learning (Franklin et al., 2014). The Cronbach's alpha coefficient was 0.83 for the French version of the questionnaire (Simoneau et al., 2012), and in our study, the Cronbach's alpha coefficients were 0.85 for the SIM group and 0.90 for the questionnaire with the adapted items for the CPG.

\section{Self-Confidence}

Self-confidence was measured by a translated version in French (ECEA) of the NLN's Self-Confidence in Learning Using Simulation Scale (Jeffries, 2007; Jeffries \& Rizzolo, 2006). This questionnaire is a five-point Likert-type scale composed of eight items measuring the students' self-confidence in their nursing problem-solving skills and their ability to learn. Again, the method for the transcultural translation and validation of this questionnaire in French is 
described elsewhere, with the French version respecting the metrological qualities of the English version (Simoneau et al., 2012). A higher score in this questionnaire means greater student selfconfidence (Franklin et al., 2014). The Cronbach's alpha coefficient for the French version of the questionnaire is 0.74 (Simoneau et al., 2012). Items in this questionnaire were adapted for the clinical placement students for our study. The Cronbach's alpha coefficients calculated in our study were 0.89 for the SIM group and 0.85 for the CPG.

\section{Student-Perceived Support}

The support received from the clinical placement preceptors or clinical simulation tutors, as perceived by the students, was measured by a questionnaire commonly used to assess teaching and designed by the Centre de Pédagogie Universitaire of the academic setting. This questionnaire included seven items answered on a five-point Likert-type scale, which evaluated the students' perceptions of the learning support, explanations provided, interest in the learning and progression, and constructive feedback offered. A total score was calculated ranging from 7 to 35 . Arbitrarily determined, a score of 7 means that the student felt unsupported; 8 to 14, slightly supported; 15 to 21, neutral; 22 to 28, supported; and 29 to 35, very supported. The Cronbach's alpha calculated for this questionnaire of seven items in our study was 0.93 .

\section{Simulation Design Characteristics}

The fifth questionnaire measured the conceptual elements of the pedagogical design of the clinical simulation (Jeffries, 2007, 2012) and was administered only to the SIM group. This questionnaire is a French translation of the Simulation Design Scale (Jeffries \& Rizzolo, 2006), respecting the metrological qualities of the English version following the transcultural translation and validation (Simoneau et al., 2012). This five-point Likert-type scale measures the students' perception regarding the presence and importance of components of the clinical simulation's pedagogical design, each subdivided into five subscales: (a) objectives and information provided, (b) support for the student, (c) problem solving, (d) feedback and debriefing, and (e) fidelity, meaning the level of realism (Jeffries \& Rizzolo, 2006). The first and third subscales had five items, the second and fourth subscales were each composed of four items, and the fifth subscale had two items (Franklin et al., 2014). For all subscales, higher scores indicate significantly higher appreciation (presence and importance) of the simulation design (Franklin et al., 2014). The Cronbach's alpha coefficient of the French version is 0.89 for the portion of the scale measuring the perception of the presence of pedagogical elements and 0.92 for the portion measuring the importance of the presence of pedagogical elements (Simoneau et al., 2012). Our Cronbach's alpha coefficients ranged from 0.75 to 0.86 for all five subscales of the presence component, with 0.91 for the 20 items composing this scale. For the importance component, Cronbach's alpha coefficients varied from 0.70 to 0.92 for the five subscales, with 0.92 for the 20 items in total.

\section{Demographic Questionnaire}

Students completed a demographic questionnaire to provide a general profile, including age, gender, previous academic preparation, previous experience in the perinatal domain, and the reasons for choosing 2 days of clinical simulations or 10 days of clinical placement. For the CPG, a question was added to specify the location of the clinical placement (hospital and care unit).

\section{Data Analysis}

The mean scores obtained in all questionnaires (knowledge, satisfaction, confidence, and support) were compared between the two groups using the Student $t$-test for independent samples. 
For knowledge acquisition, the mean of the numerical equivalent of the letter grade based on the university's guideline was used for comparing groups with the independent samples Student's $t$ test. Data from the simulation design characteristics questionnaire and the demographic data were analyzed with descriptive statistics (mean and standard deviation). All statistical analysis were conducted with SPSS v.25, and significance was set at $p<.05$ two-sided.

\section{Results}

\section{Participant Characteristics}

Eighty students participated in the study, 25 in the SIM group and 55 in the CPG. The average age of the students was 22.85 years. More female students participated in the study: 69 females $(86.25 \%)$, compared to 11 males (13.75\%). For the CPG, the students were divided into four perinatal care units: 9 in the delivery room $(16.4 \%), 5$ in the postpartum unit $(9.1 \%), 3$ in the neonatal unit $(5.5 \%)$, and 38 in the mother-child birthing unit $(69.1 \%)$.

\section{Knowledge Acquisition}

Learning was assessed using three different academic evaluations. Comparisons of the results of these three evaluations for both groups are presented in Table 1. The SIM group students scored higher on their final exam, but the difference was not statistically significant $(p>.05)$. The mean scores on the other two evaluations are also not significantly different between the two study groups.

\section{Table 1.}

Comparison of the Mean Scores Obtained by the SIM Group and the CPG Group for the Clinical Skills Evaluation, the Clinical Written Evaluation and the Final Examination $(\mathrm{N}=80)$

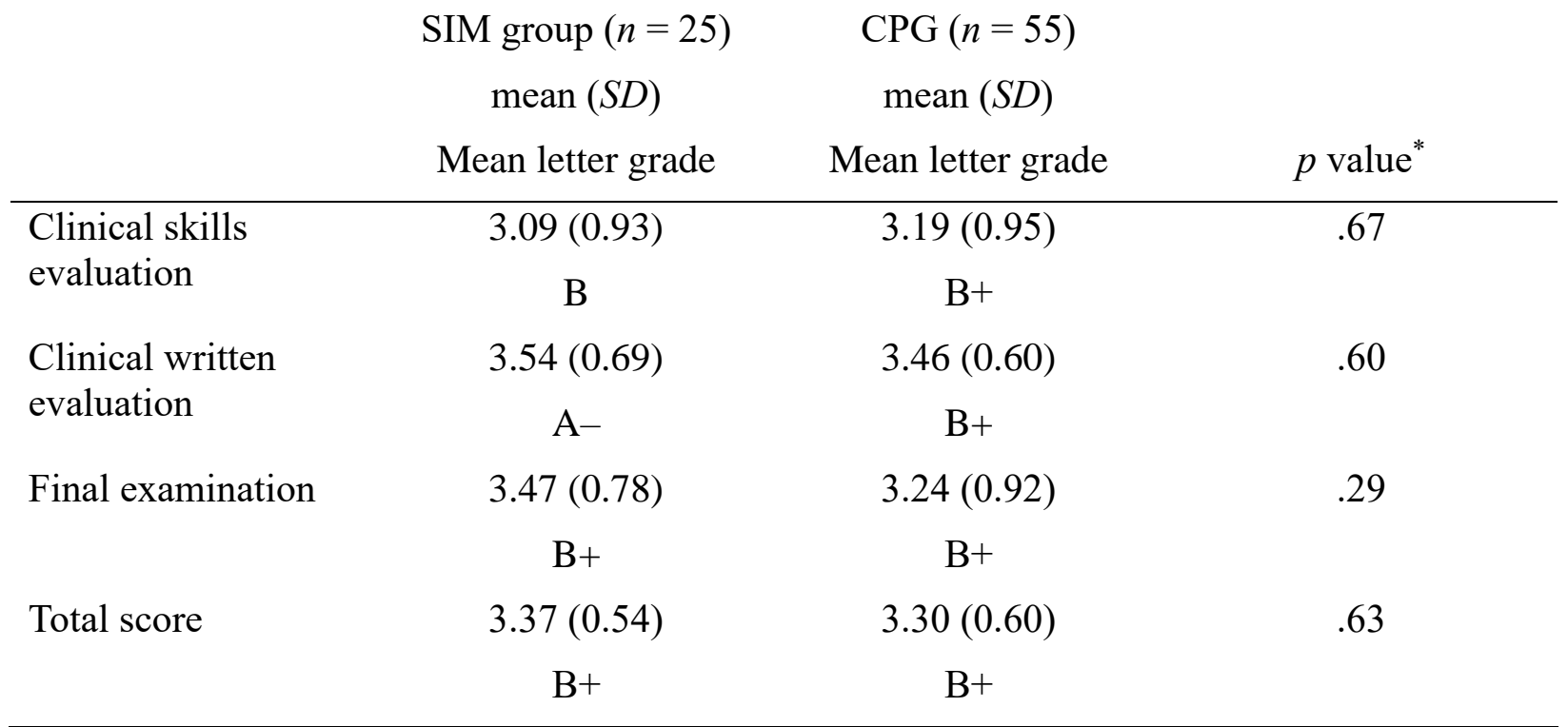

${ }^{*}$ Student's $t$-test for independent samples.

\section{Satisfaction, Self-Confidence, and Perceived Support}

The comparison of the SIM group and CPG scores for satisfaction, self-confidence, and perceived support are presented in Table 2. The mean score for satisfaction in the SIM group was 19.84 while the mean for the CPG was 21.84. The difference between the two groups was not 
statistically significant $(p=.054)$. In terms of self-confidence, the CPG students were significantly more confident in their nursing problem-solving skills and ability to learn than the SIM group students $(p=.042)$. Finally, regarding perceived support, the CPG students felt they received significantly more support from their preceptor than the SIM group students felt they received from their tutor $(p=.026)$.

\section{Table 2.}

Comparison of the Mean Scores of the SIM Group and the CPG Group for Satisfaction, SelfConfidence and Student-Perceived Support ( $\mathrm{N}=79)$

\begin{tabular}{lccc} 
& $\begin{array}{c}\text { SIM group }(n=25) \\
\text { mean }(S D)\end{array}$ & $\begin{array}{c}\text { CPG }(n=54)^{\mathrm{a}} \\
\text { mean }(S D)\end{array}$ & $p$ value $^{\mathrm{b}}$ \\
\hline Satisfaction & $19.84(3.6)$ & $21.67(4.0)$ & .054 \\
Self-confidence & $28.56(5.2)$ & $30.89(4.4)$ & $.042^{*}$ \\
Student-perceived support & $27.50(6.0)$ & $30.65(5.5)$ & $.026^{*}$
\end{tabular}

${ }^{\mathrm{a}}$ One is missing. ${ }^{\mathrm{b}}$ Student's $t$-test for independent samples.

$* p<.05$

\section{Simulation Design Characteristics Evaluation}

Results for the simulation design characteristics evaluation are presented in Table 3. Overall, the mean score for the presence of teaching practices was 75.20. For perceived importance, the mean score was 90.60. More specifically, the SIM group students assessed the presence of instructional practices as follows: (a) objectives and information provided, 19.28/25; (b) support for the student, 14/20; (c) problem solving, 20.68/25; (d) feedback and debriefing, 16.76/20; and (e) fidelity, 7.48/10. In terms of the perceived importance of the instructional practices, the SIM group students assessed it as follows: (a) presence of goals and information, 22.64/25; (b) support, 17.96/20; (c) problem solving, 22.30/25; (d) feedback and debriefing, 18.56/20; and (e) fidelity, 9.16/10. 
Table 3.

Means of the Subscale Scores in Total Simulation Design Characteristics from the SIM Group (n $=25$ )

\begin{tabular}{lccc} 
& $\begin{array}{c}\text { Perceived presence } \\
\text { of teaching practices } \\
\text { mean }(S D)\end{array}$ & $\begin{array}{c}\text { Importance of } \\
\text { teaching practices } \\
\text { mean }(S D)\end{array}$ & Possible total scores \\
\hline $\begin{array}{l}\text { Objectives and } \\
\text { information } \\
\text { Support }\end{array}$ & $19.28(3.2)$ & $22.64(2.1)$ & 25 \\
Problem resolution & $14.00(4.0)$ & $17.96(2.4)$ & 20 \\
$\begin{array}{l}\text { Commentaries and } \\
\text { debriefing }\end{array}$ & $13.76(4.5)$ & $22.30(3.1)$ & 25 \\
& & $18.56(2.4)$ & 20 \\
Fidelity & $7.48(2.1)$ & $9.16(9.2)$ & 10 \\
Total & $75.20(13.3)$ & $90.60(8.5)$ & 100 \\
\hline
\end{tabular}

\section{Discussion}

This study compared nursing students who took part in either 2 days of clinical simulations or 10 days of clinical placement in perinatal care through self-selection in either group. The results revealed little difference in terms of the students' knowledge acquisition, satisfaction, selfconfidence, and perceived support. Students' learning was found to be similar in both groups (mean of B+ in SIM group and CPG, $p=.63$ ), regrouping the clinical skills evaluation, the clinical written evaluation work, and the final exam, showing that both groups met the learning objectives of the perinatal care course. Of the three course evaluation modalities, only the results of the clinical skills evaluation were higher in the CPG, while the SIM group scored higher on the clinical care plan, but these differences were not statistically different. The results of our comparative study are like those of previous studies. There were no significant differences in the learning of nursing students studying perinatal care when $25 \%$ of the clinical placement was replaced by clinical simulation compared to a full clinical placement (Raman et al., 2019). As well, in a survey, no significant statistical difference was found between groups of students when $25 \%$ or $50 \%$ of the clinical placement was replaced by a clinical simulation (Hayden et al., 2014). The results of our study therefore reinforce the previously cited data that student learning is similar whether they participate in a clinical placement or clinical simulations replacing $100 \%$ of the clinical placement. Still, after their systematic review comparing clinical simulation substituting part of clinical placements, Bogossian et al. (2019) concluded that further studies are required to determine in what proportion the clinical simulations should replace the clinical placements.

Although no statistical differences were found, the satisfaction of the CPG students in our study is higher than the SIM group students $(p=.054)$. This could be explained by the students' 
desire to care for real patients in an authentic environment. In fact, being able to participate in patient care during clinical placements is a criterion identified by nursing students as enhancing their satisfaction with their clinical placement (Lamont et al., 2015). Clinical settings are environments in which it is possible to experience real interactions and human relationships with patients. This could explain why the CPG students in our study were more satisfied with their experience than those in the SIM group. Moreover, in all the other nursing classes in the bachelor of nursing degree at the university, students are accustomed to the experience of clinical placement. This familiarity may explain why students were more satisfied with the clinical placement experience compared to the SIM group; students are less acquainted with clinical simulations.

The results of our study also show that the CPG students are slightly significantly more confident about their learning than those in the SIM group $(p=.042)$. It seems reasonable to conclude that the students who took part in the clinical placement group had more time (10 days) in a well-known environment to develop confidence in their learning compared to those who had only 2 days in the clinical simulation in a new learning environment. Conversely, a recent integrative systematic review of the literature showed that students' confidence in their learning is optimized by clinical simulation compared to standard methods, such as clinical placements (Labrague et al., 2019). More precisely, clinical simulation increases students' self-confidence in patient management and when performing care procedures (Labrague et al., 2019; Livine, 2019). If more days of clinical simulation further focused on perinatal care procedures had been offered to the SIM students, they might have had more confidence in their learning.

The CPG students felt they received more support from their preceptor than the SIM group students did from their tutor $(p=.026)$. Previous studies confirm that satisfaction with the placement preceptor, including support received, is influenced by a daily presence, providing clinical supervision throughout the placement (Lamont et al., 2015). Nurses supervising students in clinical settings are dedicated to developing an interpersonal relationship that facilitates student learning (Lamont et al., 2015). Accordingly, our findings can be explained by the fact that students in the CPG had 10 days to develop a one-to-one relationship with the same preceptor, while in the SIM group, each tutor had a group of six students and only 2 days to create a relationship.

Finally, for the evaluation of the simulation design characteristics, the SIM group students felt that the five design characteristics were present and very important overall. The students gave higher scores for the importance of each design characteristic than for its presence. This may indicate that they wanted each design characteristic to be even more present in the scenarios. The design characteristic that received the lowest score for presence during the simulation was support. This result aligns with our other results, which show that the students in the SIM group felt they received less support than the CPG students did $(p=.026)$.

\section{Limitations}

There are several limitations to consider with this study. First, the small sample size of our study because of the limited number of students available may not be representative of all undergraduate nursing students taking a perinatal care course. Also, the CPG was composed of more than twice the number of students $(n=55)$ as in the SIM group $(n=25)$, which might have influenced our findings. Second, although the perceived support questionnaire was based on the Jeffries model (Jeffries, 2005, 2012), it was not validated before its use. Furthermore, the participants chose whether to participate in the 1-day clinical placement or the 2-day simulation sessions. We do not know whether the results would have been the same if the study was 
randomized and the participants were not permitted to choose between the two options. Also, nursing students are used to clinical placement rather than clinical simulation, so it might have been more difficult for them to adapt to the simulation environment. Finally, we did not measure skills performance in our study as it was not considered as a relevant variable for the students' learning in the perinatal course.

\section{Nursing Education Implications}

Our results showed that providing adequate support by implementing strategies to enable students to consolidate their satisfaction and self-confidence in their learning during clinical simulations is key for nursing programs. Because the students in the SIM group developed the expected knowledge and competencies of the perinatal course, this type of educational method, substituting the entire clinical placements, could be implemented in nursing education programs. This could enhance the reliability of clinical simulation scenarios, which are new for students and may create uncertainty, which may be evaluated in further research.

\section{Research Implications}

This comparative study is one of the few studies comparing nursing students who participate in a clinical placement to students who participate only in clinical simulation in the context of a perinatal care course. Future studies should concentrate on comparing knowledge acquisition, critical thinking, and other outcomes of interest in students who participate in clinical placements or simulations, to guide educational practices in the perinatal care area, as well as in any other clinical areas. Future studies should randomly assign students to study groups, and larger sample sizes should be considered. Finally, conducting a mixed-method study could potentially offer more information concerning students' support or satisfaction.

\section{Conclusions}

This study is innovative as it compares nursing students who participated in a clinical placement to students who participated only in clinical simulations in the context of a perinatal care course. Interestingly, our results align with the previous studies, which compared nursing students who participated in a clinical placement to nursing students whose clinical placement was partly replaced by some clinical simulation. However, more studies randomizing larger samples of nursing students to clinical placement or only clinical simulation are needed to confirm our results and provide reliability to this new pedagogy in nursing education. Nevertheless, our current results show that the learning of nursing students in a perinatal care course is equivalent whether they participate in clinical placement or simulation, which is encouraging for educational institutions that are unable to offer every student the opportunity to take part in a clinical placement because of limited available places. 


\section{References}

Bogossian, F. E., Cant, R. P., Ballard, E. L., Cooper, S. J., Levett-Jones, T. L., McKenna, L. G., Ng, L. C., \& Seaton, P. C. (2019). Locating "gold standard" evidence for simulation as a substitute for clinical practice in prelicensure health professional education: A systematic review. Journal of Clinical Nursing, 28(21-22), 3759-3775. https://doi.org/10.1111/jocn.14965

Canadian Association of Schools of Nursing. (2015). Domaine de pratique au niveau du baccalauréat en sciences infirmières : Lignes directrices pour les stages cliniques et la simulation. https://www.casn.ca/wp-content/uploads/2015/11/Draft-FR-clinical-sim2015.pdf

Canadian Association of Schools of Nursing. (2016). Statistiques sur la formation d'infirmières et d'infirmiers au Canada 2014-2015. Effectifs infirmiers autorisés, production canadienne : nouvelle offre potentielle. Canada Retrieved from https://www.casn.ca/wpcontent/uploads/2016/11/2014-2015-FR-SFS-FINAL-REPORT-supressed-updated-1.pdf

Cant, R. P., \& Cooper, S. J. (2010). Simulation-based learning in nurse education: systematic review. Journal of Advanced Nursing, 66(1), 3-15. https://doi.org/10.1111/j.13652648.2009.05240.x

Franklin, A. E., Burns, P., \& Lee, C. S. (2014). Psychometric testing on the NLN Student Satisfaction and Self-Confidence in Learning, Simulation Design Scale, and Educational Practices Questionnaire using a sample of pre-licensure novice nurses. Nurse Education Today, 34(10), 1298-1304. https://doi.org/10.1016/j.nedt.2014.06.011

Hanshaw, S. L., \& Dickerson, S. S. (2020). High fidelity simulation evaluation studies in nursing education: A review of the literature. Nurse Education in Practice, 46, 102818. https://doi.org/10.1016/j.nepr.2020.102818

Hartigan-Rogers, J. A., Cobbett, S. L., Amirault, M. A., \& Muise-Davis, M. E. (2007). Nursing graduates' perceptions of their undergraduate clinical placement. International Journal of Nursing Education Scholarship, 4, Article9. https://doi.org/10.2202/1548-923X.1276

Hayden, J. K., Smiley, R. A., Alexander, M., Kardong-Edgren, S., \& Jeffries, P. R. (2014). The NCSBN National Simulation Study: A longitudinal, randomized, controlled study replacing clinical hours with simulation in prelicensure nursing education. Journal of Nursing Regulation, 5(2 Suppl.), S3-S40. https://doi.org/10.1016/S2155-8256(15)30062$\underline{4}$

Horstmanshof, L., \& Moore, K. A. (2016). Understanding the needs of all the stakeholders: Issues of training and preparation for health work students and their clinical educators. Asia-Pacific Journal of Cooperative Education, 17(2), 93-100.

Howard, V. M., Englert, N., Kameg, K., \& Perozzi, K. (2011). Integration of simulation across the undergraduate curriculum: Student and faculty perspectives. Clinical Simulation in Nursing, 7(1), e1-e10. https://doi.org/10.1016/j.ecns.2009.10.004

Jeffries, P. R. (2005). A framework for designing, implementing, and evaluating simulations used as teaching strategies in nursing. Nursing Education Perspectives, 26(2), 96-103. 
Jeffries, P. R. (2007). Simulation in nursing education: From conceptualization to evaluation. National League for Nursing.

Jeffries, P. R. (2012). Simulation in nursing education: From conceptualization to evaluation (3nd ed.). National League for Nursing.

Jeffries, P. R., \& Rizzolo, M. A. (2006). Designing and implementing models for the innovative use of simulation to teach nursing care of ill Adults and children: A national, multi-site, multi-method study. National League for Nursing; Laerdal Medical.

Labrague, L. J., McEnroe-Petitte, D. M., Bowling, A. M., Nwafor, C. E., \& Tsaras, K. (2019). High-fidelity simulation and nursing students' anxiety and self-confidence: A systematic review. Nursing Forum, 54(3), 358-368. https://doi.org/10.1111/nuf.12337

Lamont, S., Brunero, S., \& Woods, K. P. (2015). Satisfaction with clinical placement: The perspective of nursing students from multiple universities. Collegian, 22(1), 125-133. https://doi.org/10.1016/j.colegn.2013.12.005

Larue, C., Pepin, J., \& Allard, É. (2015). Simulation in preparation or substitution for clinical placement: A systematic review of the literature. Journal of Nursing Education and Practice, 5, 132-140. https://doi.org/10.5430/jnep.v5n9p132

Livine, N. (2019). High-fidelity simulations offer a paradigm to develop personal and interprofessional competencies of health students: A review article. The Internet Journal of Allied Health Sciences and Practice, 17(2), Article 8.

Raman, S., Labrague, L. J., Arulappan, J., Natarajan, J., Amirtharaj, A., \& Jacob, D. (2019). Traditional clinical training combined with high-fidelity simulation-based activities improves clinical competency and knowledge among nursing students on a maternity nursing course. Nursing Forum, 54(3), 434-440. https://doi.org/10.1111/nuf.12351

Simoneau, I. L., Ledoux, I., \& Paquette, C. (2012). Efficacité pédagogique de la simulation clinique haute-fidélité dans le cadre de la formation Collégiale en soins infirmiers [Rapport de recherche PA2010-004 : Programme d'aide à la recherche sur l'enseignement et l'apprentissage].

Smith, P. M., Corso, L. N., \& Cobb, N. (2010). The perennial struggle to find clinical placement opportunities: a Canadian national survey. Nurse Education Today, 30(8), 798-803. https://doi.org/10.1016/j.nedt.2010.02.004

Smith, P. M., Spadoni, M. M., \& Proper, V. M. (2013). National survey of clinical placement settings across Canada for nursing and other healthcare professions--who's using what? Nurse Education Today, 33(11), 1329-1336. https://doi.org/10.1016/j.nedt.2013.02.011

Young, P. K., \& Shellenbarger, T. (2012). Interpreting the NLN Jeffries Framework in the context of nurse educator preparation. Journal of Nursing Education, 51(8), 422-428. https://doi.org/10.3928/01484834-20120523-02 